\title{
Identification of Velocity Variations in a Seismic Cube Using Neural Networks
}

\author{
Dario Sergio Cersósimo, Claudia Ravazoli, Ramón García-Martínez \\ PhD Program \& Geophisic Group of the Astronomic \& Geophisic Science School. \\ University of La Plata \\ PETROBRAS ENERGIA Exploración ARGENTINA \\ Software \& Knowledge Engineering Center. Graduate School. Buenos Aires Institute of \\ Technology \\ Intelligent Systems Laboratory. School of Engineering. University of Buenos Aires. \\ rgmeitba . edu .ar
}

\begin{abstract}
This research allow to infer that from seismic section and well data it is possible to determine velocity anomalies variations in layers with thicknesses below to the seismic resolution using neuronal networks.
\end{abstract}

\section{Introduction}

The intelligent systems [Holland et al., 1987; Towell \& Shavlik, 1994; GarcíaMartinez \& Borrajo, 2000, Grosser et al.,2005] have shown to be very useful in prospective problems in which other approaches have failed. The neuronal networks as a particular case of intelligent systems [Hertz et al., 1991; Rich \& Knight, 1991; Setiono \& Liv, 1996; Yao \& Liu, 1998], have given promising results in fields like: modeling, analysis of time series, patterns recognition among others [Dow \& Sietsma, 1991; Gallant, 1993; Back et al., 1998], In the field of the geosciences this type of systems has contributed with conventional and no conventional developments of interpretation and processing [Heggland et al., 1999a; 1999b; 2000; An \& Moon, 1993; Johnston, 1993; Wang \& Huang, 1993; Ping, 1994; Cai, 1994; Huang \& Williamson, 1994; Zhang et al., 1995a; 1995b, Sun et al., 2001; Deker et al., 2001; Chengdang, 1993].

One open issue in high resolution inversion is that there is no way to obtain from seismic data the top and the base of a geologic formation with a thickness under 15 meters (approximately). Considering that the observed seismic trace can be seen as the real component of a complex trace, attributes as envelope amplitude, phase and frequency can be separated and calculated. Each one of these attributes and the combination of them could show the characteristics and petrophisical variations of the rock.

One of the petrophysical characteristics is the lateral velocity variation. These velocity variations can be inferred through a neuronal network having as input wells synthetic data and the calculation of the trace attributes as envelope amplitude, phase and frequency on an interpreted seismic horizon.

Please use the following format when citing this chapter:

Cersósimo, D.S., Ravazoli, C., García-Martínez, R., 2006, in IFIP International Federation for Information Processing, Volume 218, Professional Practice in Artificial Intelligence, eds. J. Debenham, (Boston: Springer), pp. 11-19. 


\section{Treatment of the Data}

For the experimental treatment it has been started from a synthetic geologic model. From this synthetic geologic model it has been calculated a synthetic seismic section (direct method). A synthetic geologic model of parallel layers was used. Gas velocity and petroleum velocity have been assigned to some of these layers. As it is observed in Figure 1, we have five layers, the third layer (yellow) is around ten meters of thickness. This layer has lateral and vertical velocities variation (Table 1).

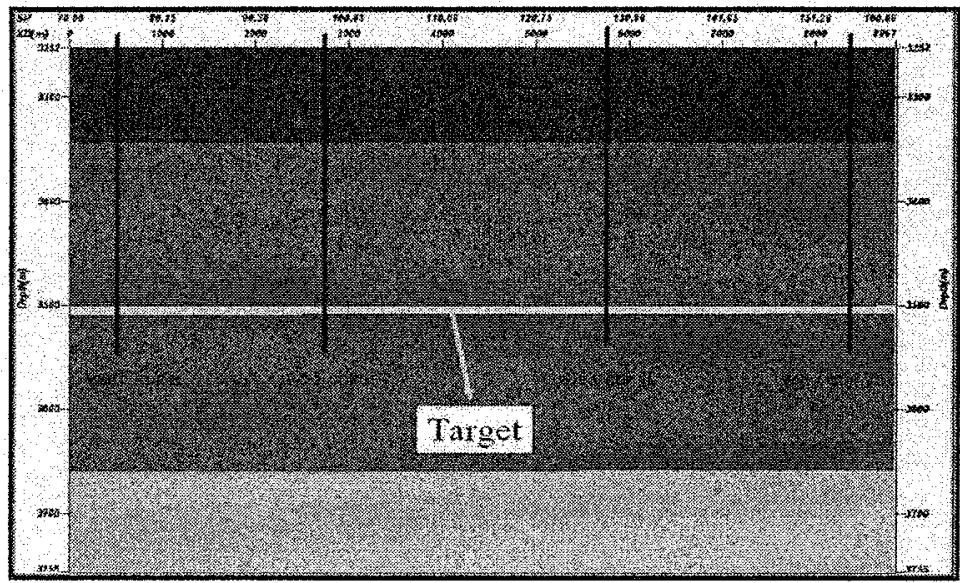

Fig. 1. Geological Model

\begin{tabular}{|c|c|c|c|c|c|c|}
\hline NAME & PATTERN & DIST & VTOP & VBOT & DTOP & DBOT \\
\hline & & 0.00 & 350000 & 3500.00 & 2375724 & 2375.724 \\
\hline & & 8866.80 & 3500000 & 3500.00 & 2375724 & 2375.724 \\
\hline \multirow[t]{2}{*}{$\mathrm{C2}$} & & 0.00 & 3500.00 & 350000 & 2375724 & 2375.724 \\
\hline & & 8866.80 & 3500.00 & 3500,00 & 2375.724 & 2375,724 \\
\hline \multirow{3}{*}{$\mathrm{C3}^{3}$} & & 0.00 & 3467.00 & 3467.00 & 2370104 & 2370104 \\
\hline & Well 1 & 200000 & 3467,00 & 3467.00 & 2370.104 & 2370.104 \\
\hline & & 2500.00 & 3380.00 & 3467.00 & 2355.093 & 2370104 \\
\hline \multirow[t]{4}{*}{ CDP } & Well 2 & 300000 & 3380000 & 346700 & 2355093 & 2370,104 \\
\hline & & 3500.00 & 3467.00 & 340700 & 2370.104 & 2370.104 \\
\hline & & 5000.00 & $3467 \mathrm{og}$ & 3467.00 & 2370,104 & 2370,104 \\
\hline & & 550000 & 3380000 & 3467,00 & 2355.093 & 2370.104 \\
\hline \multirow[t]{2}{*}{$\mathrm{CDP}$} & Well 3 & 6000.00 & 3380.00 & 3467,00 & 2355,093 & 2370.104 \\
\hline & & 6500.00 & 3467.00 & 346700 & 2370.104 & 2370.104 \\
\hline \multirow{3}{*}{$\mathrm{C4}^{\mathrm{CDP}}$} & Well 4 & 8866.80 & 3467,00 & 3467.00 & 2370.104 & 2370.104 \\
\hline & & 0.00 & 3800,00 & 3800.00 & 2425.073 & 2425.073 \\
\hline & & 8866.80 & 3800.00 & 3800.00 & 2425.073 & 2425,073 \\
\hline \multirow[t]{2}{*}{$\mathrm{Cs}$} & & 0.00 & 3900.00 & 3900.00 & 2440.873 & 2440,873 \\
\hline & & 8866.80 & 3900.00 & 3000.00 & 2440.873 & 2440.873 \\
\hline
\end{tabular}

Table 1. Velocity field 
In Table 1 DIST is the distance from the origin, VTOP is the velocity of the top of layer, VBOT is the velocity of the base of layer, DTOP is the density of the top of the layer and DBOT is the density of the base of the layer. The involved densities has been calculated with Gardner equation [Gardner et al., 1974]. This geological model is used in the sinthetic sismic section calculation. (Figure 2).

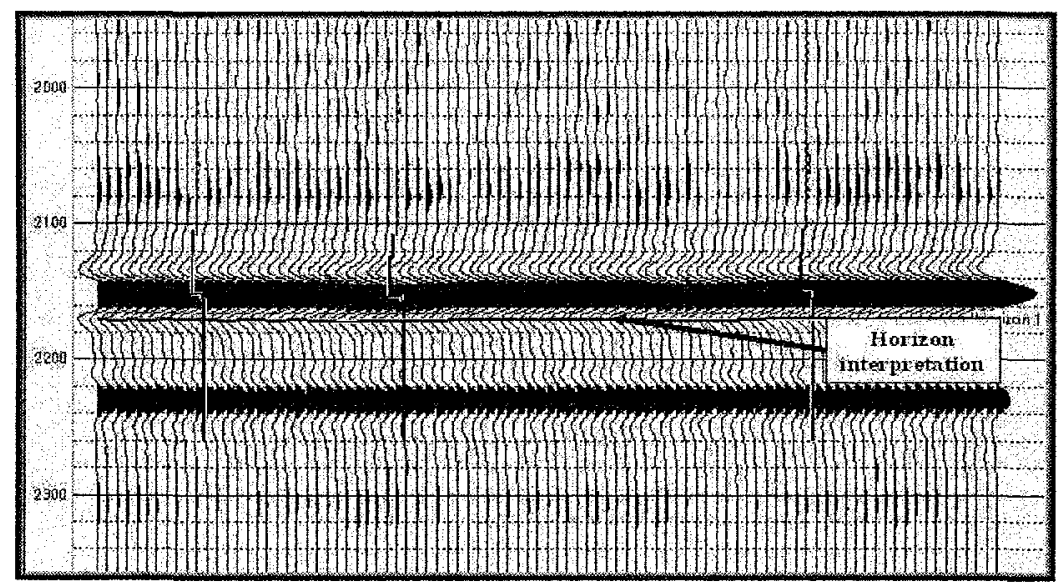

Fig. 2. Synthetic Seismic Section

The used parameters for the processing of the synthetic seismic section and for wavelets calculation are showed in Table 2. Due to the frequency content in the synthetic seismic section, it is impossible to determine the top and the base of the objective horizon. The velocity variation on the real horizon is in Fig. 3.

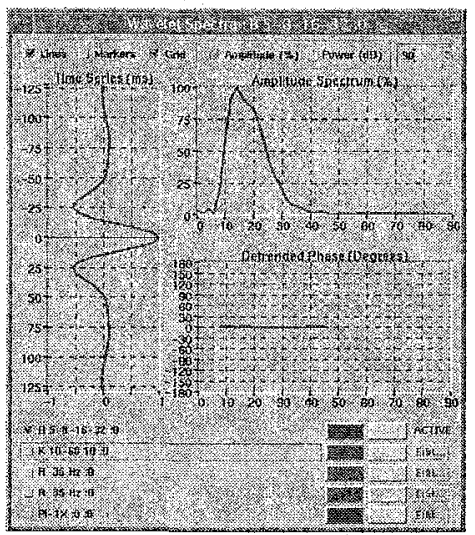

$\begin{array}{lr}\text { Start Trace } & 1 \\ \text { End Trace } & 91 \\ \text { Trace Increment } & 1 \\ \text { Trace Amplitude } & 1.00 \\ \text { Sample Rate } & 2.00 \\ \text { Start Shot Pt. } & 70.00 \\ \text { End Shot Pt. } & 160.00 \\ \text { Shot Pt. Space } & 98.52 \\ \text { Shot Pt. Incr. } & 1.00 \\ \text { Wavelet } & \text { ORMSBY } \\ \text { Frecuency 1 } & 5.0 \\ \text { Frecuency 2 } & 8.0 \\ \text { Frecuency 3 } & 16.0 \\ \text { Frecuency 4 } & 32.0 \\ \text { Phase (M=min) } & 0.0\end{array}$

Table 2. Wavelette and parameters used in the calculation of the Synthetic Seismic Section 


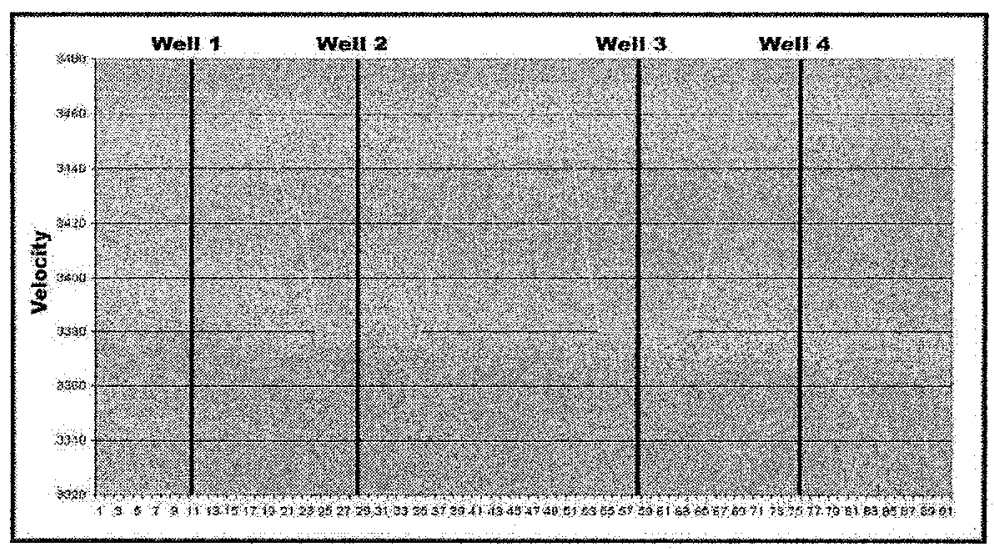

Fig. 3. Velocity variation on the Real Horizon

\section{Model Based Inversion}

In model based inversion [Russell, 1988; Treitel et al., 1993; 1995; Stewart et al., 1984], the synthetic seismic data and the data of three wells (Well 1, Well 3 and Well 4) was process in a conventional way to calculate an initial velocities model. The initial model (Figure 4) has been taken from a seismic interpretation over a horizon near the target.

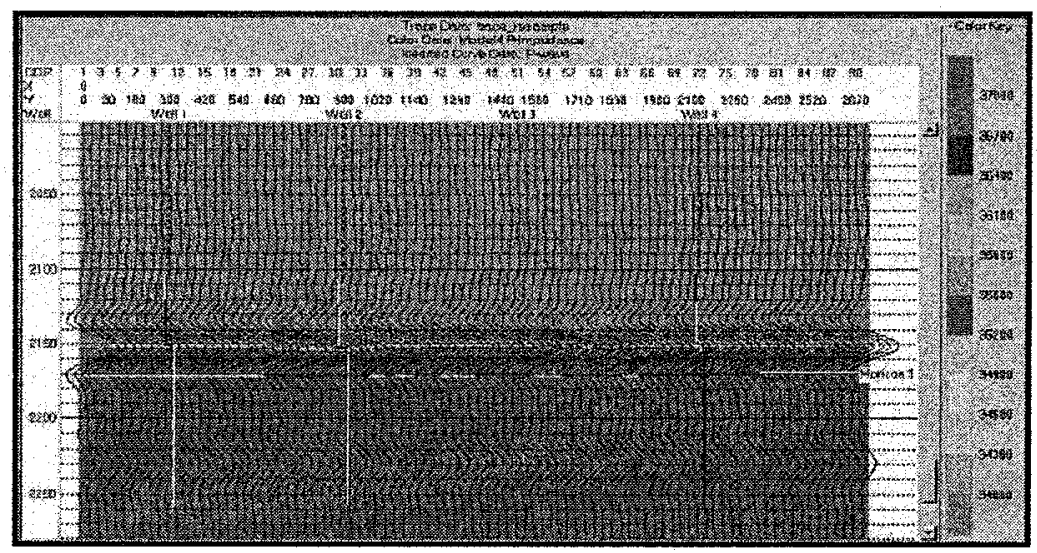

Fig. 4. Inicial Model 
When the initial velocities model is finished, this model trace would differ from the original seismic trace (fig. 2). Then least squares optimization makes the difference between the original trace and the model as small as possible. The result shown in figure 5 was reached after 50 iterations. This figure shows the velocity variation given by the model-based inversion in the target horizon. The result show that the model based inversion discriminates two low velocity zones in well 2 and well3 (2150 mseg.).

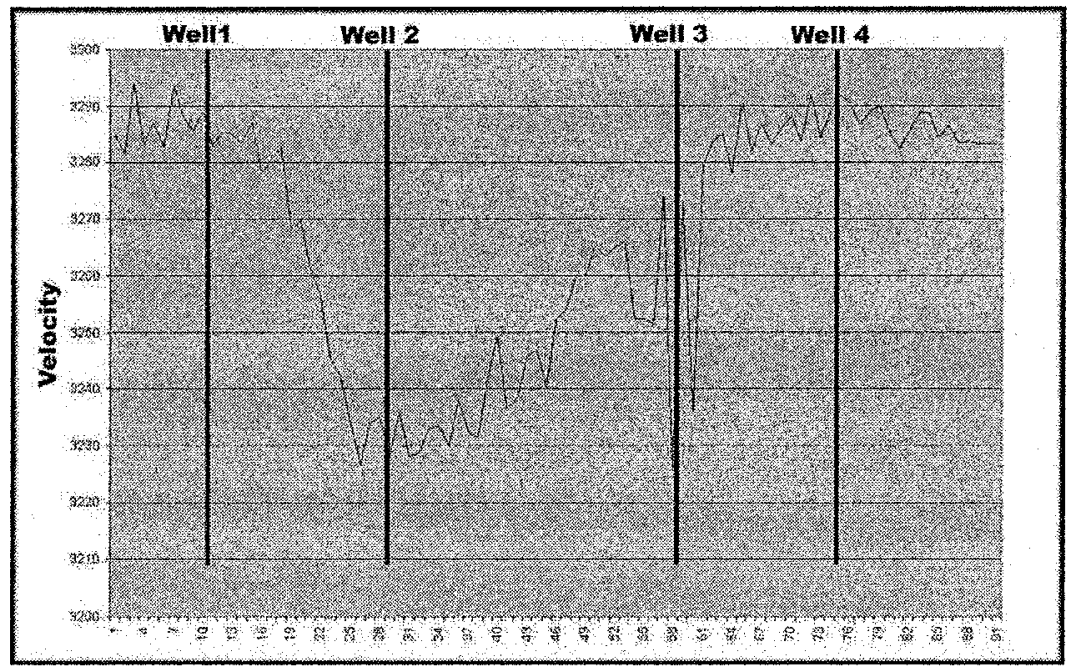

Fig. 5. Velocity variation on the target Horizon (Model Based Inversion)

\section{Artificial Neuronal Network Based Inversion}

In this approach an artificial neuronal network was applied to an interpreted horizon with a Feed Forward Back Propagation algorithm [Freeman \& Skapura; 1991, Haykin, 1998], defined with nine neurons of input, a hidden layer of five neurons and one neuron of output. The neuronal network design can be appreciated in figure 6 with their inputs and outputs.

The input data include the seismic interpretation, seismic attributes calculated from the interpreted horizon. The desired data was the velocity of the Wells from "Well1", "Well2" and "Well4" (the same input data than the model based inversion). In order to calculate the velocity in each trace with less than $1 \%$ error and 1000 iterations, the neuronal network has been trained with the three mentioned wells. The velocity as a Shot Point function (SP) and CDP's has been represented in figure 7. 


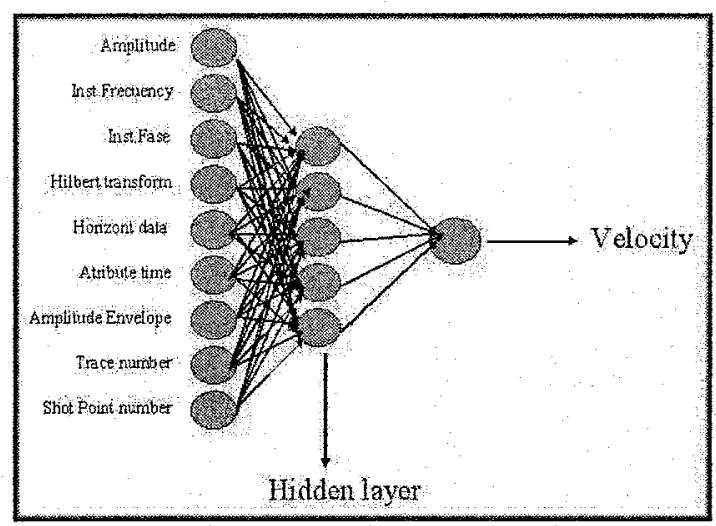

Fig. 6. Artificial Neuronal Network Design

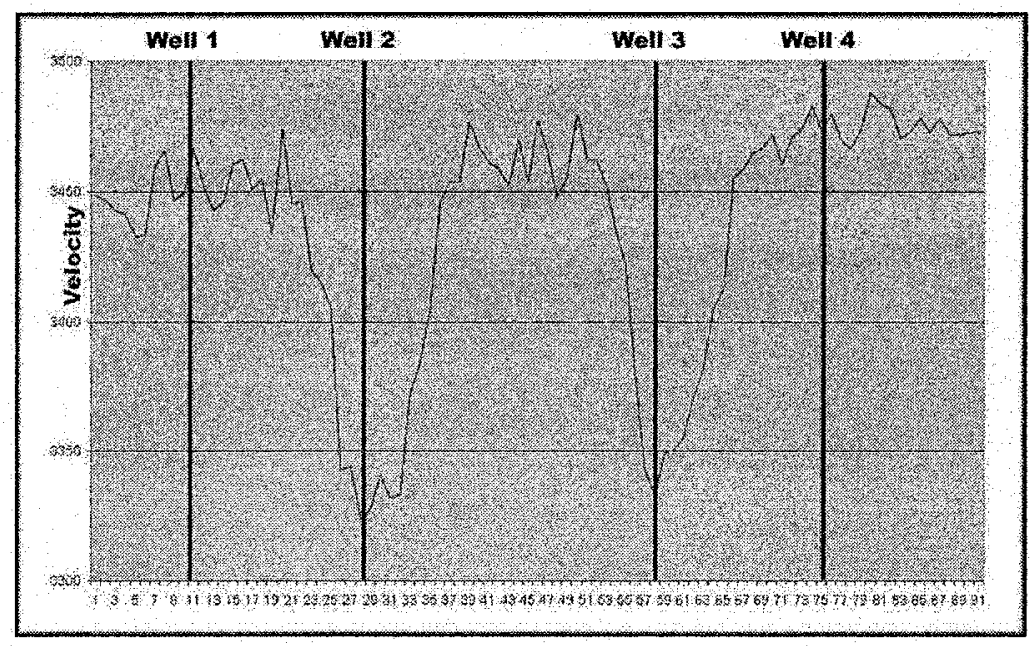

Fig. 7. Velocity variation on the target Horizon according to Artificial Neuronal Networks

It has been compared the velocity variation calculated from Model based inversion versus the one processed from artificial neuronal networks (figure 8), it is possible to observe that the neural net has been able to discriminate two low velocity zones. First one is between CDP's 22 and 37, corresponding the Well 2, and second between CDP's 52 and 70, corresponding the Well 3 . It is important to emphasize that this last zone has been predicted by the neural network successfully because the Well3 has not been used for the training of the network, this can be corroborated observing the field of velocities given in Table 1 . The intervals between $2500 \mathrm{~m}$ to $3000 \mathrm{~m}$ and $5500 \mathrm{~m}$ to 
$6000 \mathrm{~m}$, the top velocity of the yellow horizon it is $3380 \mathrm{~m} / \mathrm{seg}$, associated to the Wells2 and Well3 respectively.

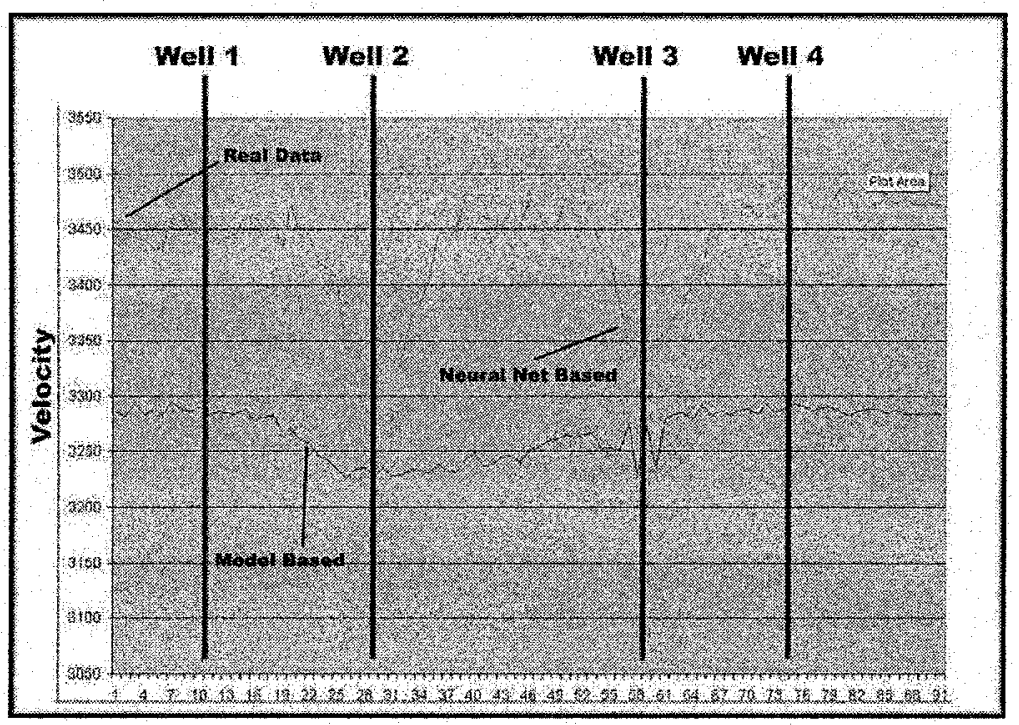

Fig. 8. Comparison of Velocity variation on the target horizon

\section{Conclusions}

The experimental goal was to obtain the velocity variation with: [a] the data of the seismic interpretation, [b] the calculated seismic attributes in the interpreted seismic horizon (amplitude, instantaneous frequency, instantaneous phase, transformed hilbert, amplitude envelope, seismic trace) and [c] the well data. The neural net was able to discriminate better the low velocity as is observed in the Well3. This result allow us to infer that it is possible to discriminate velocity variations, acoustic impedances or any other well curve throughout a section of seismic cube using neural net.

\section{References}

An, P. and Moon, W. 1993. Reservoir characterization using feedforward neural networks. 63rd Annual Internat. Mtg., Soc. Expl. Geophys., Expanded Abstracts, , 93, 258-262.

Back, B., Sere, K., \& Vanharanta, H. 1998. Managing complexity in large data bases using self-organizing maps, Accounting Management \& Information Technologies 8, 191-210. 
Cai, Y. 1994. The artificial neural network approach for hydrocarbon prediction by synthesizing multiple seismic information. 56th Mtg. Eur. Assoc. Expl. Geophys., Extended Abstracts, , 94, Session:P153.

Chengdang, Z. 1993. Application of Back-propagation Neural Networks and Simulated Annealing Technique to Well Log Interpretation. Well Logging Technology, Vol. 17, No.4.

Deker, C.; Cersosimo, D.; Castagna, J. P.; and Eissa, M.A., 2001, Geophysical reservoir characterization of Bermejo Field, Ecuador, 71 st Ann. Internat. Mtg: Soc. Of Expl. Geophys., pp. 1668-1669.

Dow R. J. y Sietsma J. 1991. Creating Artificial Neural Networks that Generalize, Neural Networks, vol. 4, no. 1, pp. 198-209.

Freeman, J. \& Skapura, , D. 1991. Neural Networks: Algorithms, Applications, and Programming Techniques.Adison-Wesley.

Gallant, S. 1993. Neural Network Learning \& Experts Systems. MIT Press, Cambridge, MA.

García Martínez, R. y Borrajo, D. 2000. An Integrated Approach of Learning, Planning \& Executing. Joumal of Intelligent \& Robotic Systems. Vol. 29, Nber 1, Páginas 47-78. Kluwer Academic Press. 2000.

Gardner, G.H.F., Gardner, L.W., and Gregory, A.R., 1974, Formation velocity and density-the diagnostic basics for stratigraphic traps: Geophysics 39, 770-780.

Grosser, H., Britos, P. y García-Martínez, R. 2005. Detecting Fraud in Mobile Telephony Using Neural Networks. Lecture Notes in Artificial Intelligence 3533:613-615.

Haykin S. 1998. Neural Networks. A Comprehensive Foundation. Second Edition. MacMillan Publishing Company (2nd Edition).

Heggland, R., Meldahl, P., Bril, B. \& de Groot, P. 1999a. The chimney cube, an example of semi-automated detection of seismic objects by directive attributes neural networks: Part I;methodology, Expanded Abstracts of the SEG 69th Annual Meeting, Houston, Oct. 31 Nov. 5 ,

Heggland, R., Meldahl, P., Bril, B. \& de Groot, P. 1999b. The chimney cube, an example of semi-automated detection of seismic objects by directive attributes \& netral networks: Part II, interpretation, Expanded Abstracts of the SEG 69th Annual Meeting, Houston, Oct. 31 Nov. 5.

Heggland, R., Meldahl, P., de Groot, P. \& Aminzadeh, F.2000. Chimneys in the Gulf of Mexico, The American Oil \& Gas Reporter, Feb. 2000.

Hertz J., A. Krogh y R. Palmer 1991. Introduction to the Theory of Neural Computation. Reading, MA: Addison-Wesley.

Holland, J. H., Holyoak, K. J., Nisbett, R. E., \& Thagard, P. R. 1987. Classifter systems, Qmorphisms, \& induction. In L. Davis (Ed), Genetic algorithms \& simulated aneling pp. 116128.

Huang, Z. \& Williamson, M. 1994. Geological pattern recognition and modelling with a general regression nearal network. Can. J. Expl. Geophys., 30, no. 1, 60-68.

Zurada, J. 1995. Introduction to Artificial Neural Systems. West Publishing Company.

Johnston, D. 1993. Seismic attribute calibration using neural networks. 63rd Annual Internat. Mtg., Soc. Expl.. Geophys., Expanded Abstracts, 93, 250-253.

Ping A. 1994. The effect of random noise in lateral reservoir characterization using feedforward neural networks. Geological Survey of Canada. 1994

Rich E. y Knight, K. 1991. Introduction to Artificial Networks. Mac Graw-Hill. Publications.

Russell, B. 1988. Introduction to Seismic Inversion Methods. Society of Exploration Geophysicists.

Setiono R. \& Liu. H. 1996. Symbolic representation of neural networks. IEEE Computer Magzine, pag. 71-77, 1996.

Sun, Q.; Eissa, M. A.; Castagna, J. P.; Cersosimo, D.; sun, S.; and Deker, C., 2001, Porosity from arificial neural network inversion from Bermejo Field, Ecuador, 71 st Ann. Internat. Mtg: Soc. Of Expl. Geophys., pp. 734-737. 
Stewart, R., Huddleston, P. and Tze Kong Kan. 1984. Seismic versus sonic velocities: A vertical setsmic profiling study: Geophysics, 49,1153-1168.

Towell G. \& Shavlik, J. 1994. Knowledge-based artificial neural networks. Artificial Intelligence, vol. 70, no. 1-2, pp. 119-165.

Treitel, S, Larry Lines, and Gary Ruckgaber Geophysical Inversion and Applications, 1993142 pages.

Treitel, S \& Essenreiter, R. 1995. Predictive Deconvolution Revisited with Neural Nets: 57 th Mtg. Eur. Assoc. Expl Geophys. Extended Abstracts, 95, Session:P065.

Yao X. y Liu X. 1998. Toward Designing Artificial Neural Networks by Evolution. Applied Mathematics \& Computation, 91(1): 83-90

Wang, J. \& Huang, Z. 1993. Neural networks for robust recognition of seismic reflection patterns. 63rd Annual Internat. Mtg., Soc. Expl. Geophys., Expanded Abstracts, , 93, 246249.

Zhang, X., Li, Y., Hu, Q. \& Feng, D. 1995a. Early-stage reservoir analysis with SOMA: A neural network approach. 65th Annual Internat. Mtg., Soc. Expl. Geophys., Expanded Abstracts, , 95, 138-141.

Zhang, X., Li, Y., Liu, F. \& Wang, L. 1995b. Estimating reservoir's lithological parameters from seismic data using neural network. 65th Annual Internat. Mtg., Soc. Expl. Geophys., Expanded Abstracts, , 95, 606-608. 